\title{
Factors associated with weaning in full term and preterm infants
}

\author{
M S Fewtrell, A Lucas, J B Morgan
}

Arch Dis Child Fetal Neonatal Ed 2003;88:F296-F301

See end of article for authors' affiliations

......................

Correspondence to: Dr Fewtrell, MRC

Childhood Nutrition

Research Centre, Institute of

Child Health, 30 Guilford

Street, London

WCIN $1 \mathrm{EH}, \mathrm{UK}$

m.fewtrell@ich.ucl.ac.uk

Accepted

4 September 2002 Background: The optimal age for the introduction of solid foods (weaning) in infants is poorly
researched yet may have implications for both short and longer term health. Many parents do not comply with current guidelines.

Objective: To determine and compare the age at weaning in term appropriate size for gestational age $(A G A)$, small for gestational age (SGA), and preterm infants, and factors associated with weaning age in these groups.

Design: Data from > 2000 infants from seven prospective randomised trails conducted between 1990 and 1997 were used to address the objectives.

Results: Most infants, term AGA, SGA, or preterm, received solids before 4 months of age. Only $2 \%$ of term infants were exclusively breast fed to 6 months of age. Formula fed infants received solids on average two weeks earlier than breast fed infants. Preterm infants were significantly more likely, and term SGA infants less likely, to receive solids at both 6 and 12 weeks after term than term AGA infants. Weight at 6 weeks of age was a stronger predictor of earlier weaning than either birth weight or weight gain from birth to 6 weeks in term infants. In preterm infants, formula feeding and maternal smoking were associated with earlier weaning.

Conclusions: Infants born in the mid 1990s were weaned on average earlier than the 4 months recommended by the Department of Health. Earlier weaning was associated with less positive health behaviours. Further research is required to provide evidence based weaning guidelines, including specific advice for SGA and preterm infants, and to investigate longer term consequences of weaning practices.
$\mathrm{T}$ here is increasing evidence that growth rate during fetal life and infancy has important long term consequences for cardiovascular risk, bone health, and brain development in term and preterm infants. ${ }^{12}$ Infant growth may be influenced by diet, ${ }^{34}$ including the age at which solid foods ${ }^{5-7}$ are introduced (henceforth referred to as weaning). The introduction of solids is associated with major changes in intake of both macronutrients and micronutrients. Yet, surprisingly, relatively little attention has been paid to the weaning period in terms of the optimal age for weaning, the nature of weaning foods, or whether this period of important dietary change influences later health and development. Limited evidence from a prospective study in Dundee suggests that early weaning is associated with increased respiratory symptoms and greater fatness at 7 years of age. ${ }^{5}$

There was a major change to the age at weaning during the period 1975-1980, after publication of the 1974 Infant feeding practice report, ${ }^{8}$ which recommended "about four months" as the minimum age for the introduction of solids (table 1). Before this report, weaning often occurred at younger ages. Interestingly, apart from a reduced incidence of coeliac disease, we do not know if the change in weaning age at this time resulted in any other effects on child health. In 1980 and 1988, the Department of Health (DoH) suggested that "few infants should require solids before 3 months and most by 6 months"..$^{10}$ Then, in 1994, the DoH report Weaning and the weaning diet suggested that mothers should begin to introduce solid foods at 4-6 months of age. ${ }^{11}$ However, robust evidence to underpin this recommendation is lacking, ${ }^{7}$ and, despite a movement towards later introduction of solids between 1995 and 2000, ${ }^{12}{ }^{13}$ many mothers in the United Kingdom seem still either unwilling or unable to follow the DoH recommendations. Whether this has implications for later health is unknown.
Recently, the WHO recommended exclusive breast feeding for at least six months as the optimal mode of infant feeding, with the introduction of solids thereafter and continued breast feeding up to or beyond 2 years of age. ${ }^{14}$ This recommendation does not included specific advice on the introduction of solids in infants who are formula fed, as infant formula is regarded as a complementary food and effectively grouped with solids. The issue of whether separate weaning advice might be appropriate for breast fed and formula fed infants has never been considered, even though there are considerable differences in early micronutrient intake, particularly iron and zinc, between the groups, which suggest that they may benefit from different first solid foods.

The most recent published information on national trends in weaning age and practices was collected between August and October 2000. ${ }^{13}$ These data are from healthy term infants and include information on the age at weaning in different regions of the United Kingdom as well as differences according to type of milk feeding and social and maternal factors. Here we present data collected between 1993 and 1997 from both term and preterm infants participating in prospective randomised trials of diet during infancy. Our datasets include anthropometric measurements, thus allowing exploration of the relation between infant size and weaning practices, which is not possible in the national feeding surveys. These data were used to determine:

- the age (and variation) at which solids are introduced in term infants, both appropriate size and small for gestational age (AGA and SGA);

Abbreviations: AGA, appropriate size for gestational age; SGA, small for gestational age 
Table 1 The percentage of infants receiving solid foods at 6 weeks, 3 and 4 months, in England and Great Britain in 1975-2000

\begin{tabular}{lllll}
\hline Location & Year & 6 weeks & 3 months & 4 months \\
\hline England & 1975 All infants & 40 & 85 & 97 \\
Great Britain & 1980 All infants & 14 & 52 & 89 \\
Great Britain & 1985 All infants & 11 & 62 & 90 \\
Great Britain & 1990 All infants & 9 & 68 & 94 \\
Great Britain & 1995 Human milk only & 1 & 30 & 84 \\
Great Britain & 1995 No human milk & 9 & 63 & 93 \\
Great Britain & 2000 Human milk only & 1 & 12 & 79 \\
Great Britain & 2000 No human milk & 3 & 28 & 88 \\
\hline \multirow{2}{*}{ Data derived from Foster et al, ${ }^{12}$ Hamlyn et al, ${ }^{13}$ and Wharton. ${ }^{24}$} & \\
\hline
\end{tabular}

- whether the type of milk feeding influences the age at which weaning foods are introduced;

- the age (and variation) at which solids are introduced in preterm infants;

- which factors influence the age of weaning in full term AGA, SGA, and preterm infants;

- whether the factors that influence the age of weaning in full term AGA infants differ from those in SGA or preterm infants.

\section{METHODS}

\section{Subjects}

Data from seven prospective randomised dietary trials of over 2000 infants were used to address the objectives. Three trials involved term AGA infants, ${ }^{15-17}$ two involved term SGA infants (birth weight $<10$ th centile for gestational age and $\operatorname{sex}^{318}$ ), and two trials involved preterm infants $(<37$ weeks gestation, ${ }^{4}$ birth weight $<2000 \mathrm{~g}$ (unpublished)). Table 2 gives the details of the studies. All were randomised trials testing dietary interventions; all but one (preterm cohort B) also included a reference group of infants, who were predominantly breast fed for at least six weeks. In the case of preterm cohort A, the breast fed group were allowed up to $2 \mathrm{oz}(60 \mathrm{ml})$ formula milk a day.

Information on feeding practices was collected prospectively in all but one study (term AGA I). At 6, 12, and 26 weeks after term, infants were reviewed at home by research nurses, and mothers were asked if they had started their infant on solid foods. In the term AGA N and preterm B studies, mothers were also asked the actual age in weeks of their infant when solids were introduced. For the term AGA I study, infants were recruited at 9 months of age, and mothers were asked to recall the age of the infant when solids were introduced. Advice on infant feeding, including recommendations on weaning, were provided by the mother's health professionals and not by research staff.

For each study, data were also collected at baseline on socioeconomic status (based on the UK Registrar General's

Table 2 Study details, including recruitment, location, design milk feeding practices, and population size

\begin{tabular}{|c|c|c|c|c|c|c|}
\hline Study & $\begin{array}{l}\text { Recruitment } \\
\text { dates }\end{array}$ & Location & Randomised intervention & Breast fed group & $\begin{array}{l}\text { Number of } \\
\text { infants }\end{array}$ & Weaning data collected \\
\hline Term AGA $(N)^{15}$ & $11 / 93-06 / 95$ & $\begin{array}{l}\text { Nottingham } \\
\text { Leicester }\end{array}$ & TF \pm LCPUFA & $\begin{array}{l}+ \\
\text { at least } 6 \text { weeks } \\
\mathrm{BF}\end{array}$ & $\begin{array}{l}F F n=224 \\
B F n=96\end{array}$ & $\begin{array}{l}\text { Prospectively at } 6,12 \text {, and } 26 \text { week } \\
\text { follow up } \\
\text { - solids introduced yet? } \\
\text { - age at introduction }\end{array}$ \\
\hline Term AGA $(I)^{16}$ & $10 / 93-05 / 95$ & $\begin{array}{l}\text { Nottingham } \\
\text { Leicester } \\
\text { Norwich }\end{array}$ & $\begin{array}{l}\text { Iron-suppl follow-on } \\
\text { formula versus cows' milk }\end{array}$ & $\begin{array}{l}+ \\
\text { at least } 6 \text { weeks } \\
\mathrm{BF}\end{array}$ & $\begin{array}{l}F F n=199 \\
B F n=288\end{array}$ & $\begin{array}{l}\text { Retrospectively at recruitment ( } 9 \text { months) } \\
\text { - age at introduction of solids }\end{array}$ \\
\hline Term AGA $(B)^{17}$ & $05 / 95-08 / 96$ & Cambridge & $\mathrm{TF} \pm \mathrm{sn}-2$ palmitate & $\begin{array}{l}+ \\
\text { at least } 6 \text { weeks } \\
\mathrm{BF}\end{array}$ & $\begin{array}{l}F F n=203 \\
B F n=120\end{array}$ & $\begin{array}{l}\text { Prospectively at } 6 \text { weeks } \\
\text { - solids introduced yet? }\end{array}$ \\
\hline Term SGA $(A)^{3}$ & $09 / 93-01 / 96$ & $\begin{array}{l}\text { Cambridge } \\
\text { Nottingham } \\
\text { Leicester }\end{array}$ & TF $v$ PDF & $\begin{array}{l}+ \\
\text { at least } 6 \text { weeks } \\
\mathrm{BF}\end{array}$ & $\begin{array}{l}F F n=242 \\
B F n=153\end{array}$ & $\begin{array}{l}\text { Prospectively at } 6,12,26 \text { weeks } \\
\text { - solids introduced yet? }\end{array}$ \\
\hline Term SGA $(B)^{18}$ & 07/90-10/91 & Cambridge & $\mathrm{TF} \pm$ carnitine & + & $\begin{array}{l}F F n=26 \\
B F n=26\end{array}$ & $\begin{array}{l}\text { Prospectively at } 6,12,26 \text { weeks } \\
\text { - solids introduced yet? }\end{array}$ \\
\hline Preterm $(A)^{4}$ & $08 / 93-10 / 96$ & $\begin{array}{l}\text { Cambridge } \\
\text { Nottingham } \\
\text { Leicester }\end{array}$ & TF $v$ PDF & + & $\begin{array}{l}F F n=206 \\
B F n=58\end{array}$ & $\begin{array}{l}\text { Prospectively at } 6,12,26 \text { weeks post } \\
\text { term } \\
\text { - solids introduced yet? }\end{array}$ \\
\hline Preterm $(B)^{*}$ & 04/95-07/97 & Glasgow & PTF then PDF \pm LCPUFA & - & $n=228$ & $\begin{array}{l}\text { Prospectively at } 6,12,26 \text { weeks post } \\
\text { term } \\
\text { - solids introduced yet? } \\
\text { - age at introduction }\end{array}$ \\
\hline
\end{tabular}

*Unpublished data

AGA, Appropriate size for gestational age; SGA, small for gestational age; FF, formula fed; BF, breast fed; LCPUFA, long chain polyunsaturated fatty acid; PTF, preterm infant formula; TF, term formula; BF, exclusively breast fed (see text); PDF, post-discharge formula. 
Table 3 Number (percentage) of term AGA infants receiving solid foods at 6, 12, and 26 weeks according to milk feeding practices

\begin{tabular}{|c|c|c|c|c|c|c|}
\hline \multirow[b]{2}{*}{ Study } & \multicolumn{2}{|l|}{6 weeks } & \multicolumn{2}{|l|}{12 weeks } & \multicolumn{2}{|l|}{26 weeks } \\
\hline & Breast fed & Formula fed & Breast fed & Formula fed & Breast fed & Formula fed \\
\hline Term AGA (N) & $0 / 92(0)$ & $14 / 224(6.25)^{*}$ & $37 / 96$ (38.5) & $160 / 224(71.4)^{* *}$ & $96 / 96(100.0)$ & $234 / 234(100.0)$ \\
\hline Term AGA (I) & $12 / 288(4.2)$ & $27 / 199(13.6)$ * * & $179 / 288(62.2)$ & $150 / 199(75.4)^{* *}$ & $283 / 288(98.3)$ & $196 / 199$ (98.9) \\
\hline Term AGA (B) & $0 / 120(0)$ & $38 / 203(18.7)^{* *}$ & $N / A$ & N/A & N/A & $N / A$ \\
\hline
\end{tabular}

Breast feeding is defined as predominantly breast fed to 6 weeks.

${ }^{*} p<0.05,{ }^{*} p<0.001$ for age of solid food introduction, breast fed $v$ formula fed within the same study.

AGA, Appropriate size for gestational age; N/A, data not available.

classification), maternal educational achievements (recorded on a five point scale ranging from no qualifications to higher professional qualifications as described previously ${ }^{19}$ ), parity, and parental smoking (during the second and third trimesters). In all studies, apart from term AGA I and preterm B, maternal and paternal weight and height were recorded; weight and height were self reported, and head circumferences measured. Although mothers who were not white were included in some of the studies, they were not necessarily representative of their ethnic group, as a requirement for inclusion was that the infant should have English as a first language (in order to complete the neurodevelopmental follow up). For this reason, the effect of ethnicity on weaning behaviour was not examined.

\section{Statistical analysis}

The proportions of infants receiving solid foods at 6,12 , and 26 weeks were compared between studies and between breast and formula fed infants using the $\chi^{2}$ test. Where available, the actual age at introduction of solids was compared between breast and formula fed infants by independent samples $t$ test. Factors associated with age (in weeks) at introduction of solids were investigated using stepwise multiple regression analyses ( $p$ value for inclusion $<0.05$ ) with age at introduction of solids as the dependent variable and potential predictors as independent variables.

\section{RESULTS}

Table 1 gives information on the cohorts. Four of the seven studies were completed between the 1995 and 2000 Infant feeding surveys. ${ }^{12}{ }^{13}$

\section{AGA cohorts}

At 6 weeks, $6.25 \%, 13.6 \%$, and $18.7 \%$ of formula fed term AGA infants in our three largest studies were reported to be receiving solid foods. By 12 weeks of age, $71.4 \%$ and $75.4 \%$ of the formula fed infants were receiving solid foods (table 3, fig 1). Both sets of figures are very similar to those reported nationally for Great Britain in 1995, ${ }^{12}$ but higher than the 2000 figures. ${ }^{13}$ At 12 weeks, fewer breast fed infants than formula fed infants within the same studies were receiving solid foods, but the numbers were still substantial $39 \%$ and $62 \%$ v $71 \%$ and $74 \%$ respectively). Almost all infants, whether breast or formula fed, were receiving solids by 26 weeks; in fact, only $2 \%$ (eight of 388) of AGA infants were reported to be exclusively breast fed at 6 months. At 6 weeks and 12 weeks, formula fed infants were significantly more likely to be receiving solids than their breast fed counterparts (table 3).

Infants who were receiving solids by 12 weeks (study N) were significantly heavier at this age than those not yet receiving solids (mean (SD) weight $6.12(0.66) v 5.90(0.66)$ $\mathrm{kg} ; \mathrm{p}=0.001)$.

\section{Term SGA cohorts}

At 6 weeks, no infant in the smaller SGA study was receiving solids, whereas in the larger study the figures were $1.5 \%$ and $3.3 \%$ for breast fed and formula fed infants respectively (table
4, fig 1). However, by 12 weeks, about one third of breast feeders and two thirds of formula feeders were receiving solids. SGA infants already receiving solids at 12 weeks were heavier
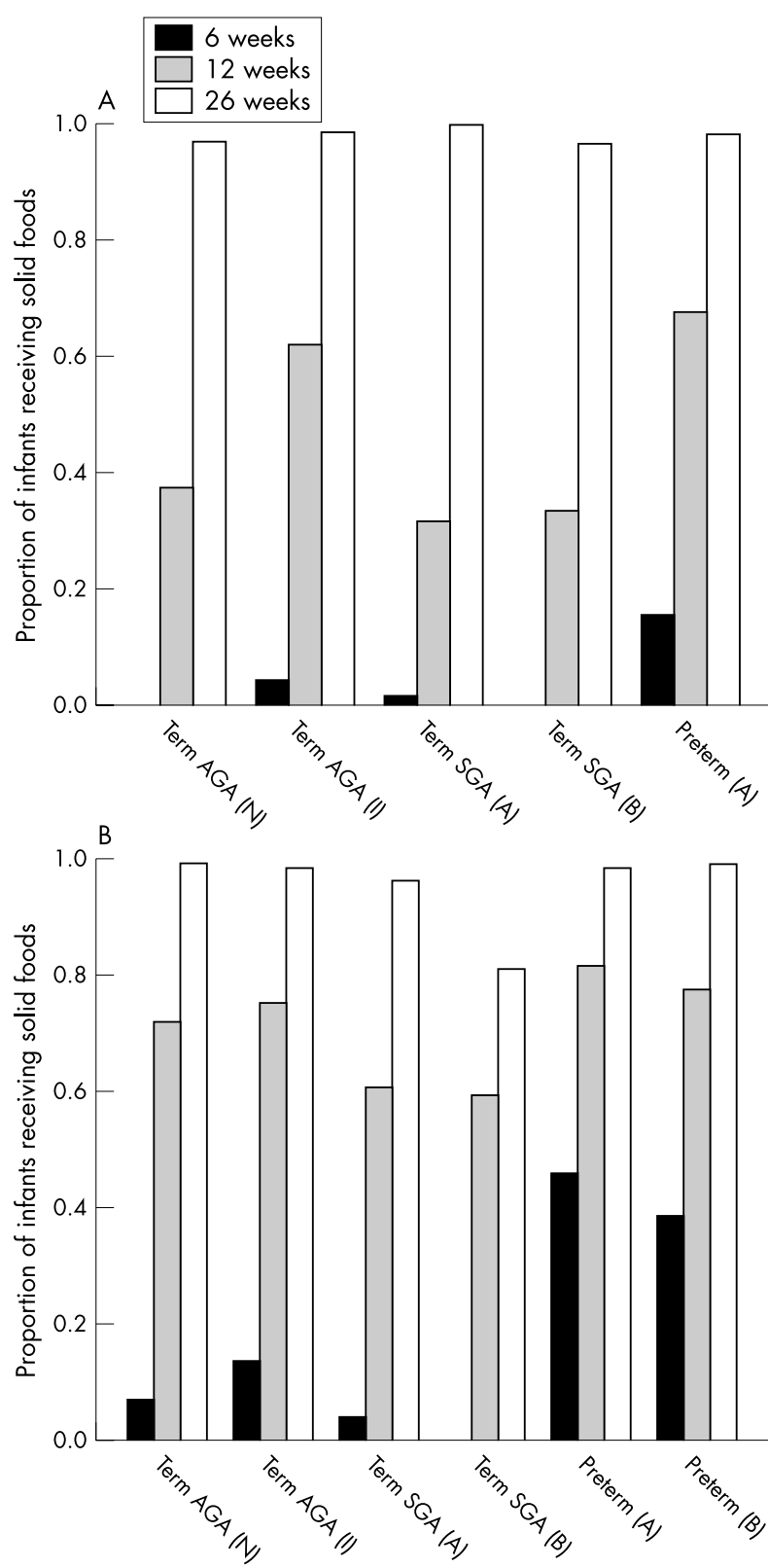

Figure 1 Proportion of infants receiving solid foods at 6, 12, and 26 weeks in different studies. (A) Breast fed infants; (B) formula fed infants. AGA, Appropriate size for gestational age; SGA, small for gestational age. 
Table 4 Percentage of term SGA and preterm infants receiving solid foods at 6, 12, and 26 weeks according to milk feeding practices

\begin{tabular}{|c|c|c|c|c|c|c|}
\hline \multirow[b]{2}{*}{ Study } & \multicolumn{2}{|l|}{6 weeks } & \multicolumn{2}{|l|}{12 weeks } & \multicolumn{2}{|l|}{26 weeks } \\
\hline & Breast fed & Formula fed & Breast fed & Formula fed & Breast fed & Formula fed \\
\hline Term SGA (A) & $2 / 153(1.3)$ & $7 / 211(3.3)$ & $46 / 146(31.5)$ & $137 / 226(60.6)^{* *}$ & $149 / 150$ (99.3) & $234 / 242$ (96.7) \\
\hline Term SGA (B) & $0 / 26(0)$ & $0 / 26(0)$ & $9 / 26(34.6)$ & $16.22(72.7)^{*}$ & $26 / 26(100)$ & $22 / 22(100)$ \\
\hline Preterm (A) & $9 / 58$ (15.5) & $91 / 198(45.9)$ ** & $39 / 58(67.2)$ & $169 / 206(82.0)^{*}$ & $53 / 54$ (98.0) & $203 / 206(98.5)$ \\
\hline Preterm (B) & N/A & $87 / 214(40.7)$ & N/A & $178 / 228$ (78.1) & N/A & $218 / 219(99.5)$ \\
\hline
\end{tabular}

Values in parentheses are percentages. Breast feeding is defined as predominantly breast fed to 6 weeks. The ages for the preterm infants represent post-term ages.

${ }^{*} p<0.05,{ }^{* *} p<0.001$ for age of solid food introduction, breast fed $v$ formula fed within the same study.

SGA, Small for gestational age; N/A, data not available.

than those not receiving solids at this age $(5.21(0.6) v 5.05$ (0.64) kg; $\mathrm{p}=0.07$ ).

The data for the three term AGA studies and the two SGA studies were combined (table 5). SGA infants were less likely to be receiving solids at 6 and 12 weeks than AGA infants; the difference reached significance for formula fed infants at 6 weeks and for both formula and breast fed infants at 12 weeks.

\section{Preterm cohorts}

As expected, preterm infants were more likely than term AGA infants to receive solids at both 6 and 12 weeks after term, with very similar figures for formula feeders from both studies at 6 weeks and 12 weeks (table 4, fig 1). Breast fed preterm infants were significantly less likely than formula fed preterm infants to be on solids at both 6 weeks (15.5\% v 45.9\%) and 12 weeks (67.2\% v 82.0\% respectively).

We compared the body weights of the preterm infants in studies A and B at 6 and 12 weeks according to whether or not they had received solids. There were significant differences in both studies; those infants receiving solids at 6 weeks were significantly heavier (4.39 and $4.45 \mathrm{~kg} v 4.0$ and $4.16 \mathrm{~kg}$ in studies A and B respectively; $\mathrm{p}<0.001$ ). The pattern at 12 weeks of age was similar $(5.28$ and $5.5 \mathrm{~kg} v 4.95$ and $5.24 \mathrm{~kg}$ in studies $\mathrm{A}(\mathrm{p}<0.05)$ and $\mathrm{B}(\mathrm{p}<0.005)$ respectively $)$.

\section{Effect of different infant formulas}

In view of the different infant formulas used in the trials, for each study we examined whether the dietary intervention influenced the age at introduction of solids (data not provided in full). The only evidence for a significant effect of the type of formula used was in preterm study A. Preterm infants randomised to receive a special nutrient enriched formula after discharge were significantly more likely to have received solids by 6 weeks than those fed a standard term formula $(55.2 \%$ v 37.4\%, $\mathrm{p}<0.05)$. However, this difference had disappeared by 12 weeks. Interestingly, term SGA infants randomised to the same formula in a parallel study were no more likely to be weaned at 6 weeks than those receiving standard term formula.
Factors associated with the age at introduction of solids Data on the actual age in weeks at the introduction of solids were available for three studies: two term AGA and one preterm. The mean weaning age for all infants, whether breast fed or formula fed, was lower than recommended in 1994 in all studies. Mean (SD) weaning ages for breast and formula fed infants in term study $\mathrm{N}$ were 14 (3.5) $v 11.9$ (3.6) weeks $(p<0.001)$, and for term study I 13 (4.4) $v 11.3$ (4.1) weeks $(\mathrm{p}<0.001)$. In both term groups, some infants were reported to be receiving solids as early as 1 week of age and some later than 26 weeks. Introduction of solid food was on average three weeks earlier in formula fed preterm infants than in term AGA infants when expressed as post-term age (8.2 (4.5) weeks; $\mathrm{p}<0.0001)$. However, the mean (SD) chronological age at introduction of solids for the preterm cohort was 17 (5) weeks (range 10-36).

Factors associated with the age at introduction of solids were explored (table 6). In all three studies, higher maternal educational achievement was associated with later weaning in simple regression models, and in the two term studies, higher social class also predicted later weaning. However, a different picture emerged in multiple regression models incorporating other potential predictors. In term AGA study N, factors associated with earlier introduction of solids were formula feeding, lower maternal age, and higher birth weight. When maternal body mass index was removed from the regression model, the effect of birth weight on solid feeding practices was lost, but the other two variables remained highly significant. To investigate the influence of size at birth versus postnatal growth on weaning age, we added the weight at 6 weeks of age and the change in weight between birth and 6 weeks to the regression model. In this model, weight at 6 weeks replaced birth weight; infants who were heaviest at 6 weeks of age were weaned earlier, regardless of birth weight or change in weight between birth and 6 weeks.

In the second term AGA (I) study, formula feeding, maternal smoking, and higher birth weight were associated with earlier introduction of solids (table 6).

In preterm study B, earlier introduction of solids was associated with the consumption of a lower proportion of human

Table 5 Percentage of term AGA and SGA infants receiving solid foods at 6, 12, and 26 weeks according to milk feeding practices

\begin{tabular}{|c|c|c|c|c|c|c|}
\hline & \multicolumn{3}{|c|}{ Breast fed } & \multicolumn{3}{|c|}{ Formula fed } \\
\hline & 6 weeks & 12 weeks & 26 weeks & 6 weeks & 12 weeks & 26 weeks \\
\hline AGA & $12 / 390$ & $2116 / 388$ & $380 / 388$ & $40 / 434$ & $300 / 420$ & $400 / 405$ \\
\hline Data combined (three studies) & $3.1 \%$ & $55.7 \%$ & $97.9 \%$ & $9.2 \%$ & $71.4 \%$ & $98.8 \%$ \\
\hline SGA & $2 / 179$ & $55 / 172 * *$ & $175 / 176$ & $7 / 233^{* *}$ & $153 / 248^{*}$ & $256 / 264$ \\
\hline Data combined (two studies) & $1.1 \%$ & $32.0 \%$ & $99.4 \%$ & $3.0 \%$ & $61.7 \%$ & $97 \%$ \\
\hline
\end{tabular}

Breast feeding is defined as predominantly breast fed to 6 weeks.

${ }^{*} p<0.05,{ }^{*} p<0.001$ for age of solid food introduction, AGA $v$ SGA at the same age.

AGA, Appropriate size for gestational age; SGA, small for gestational age. 
Table 6 Factors associated with age of weaning (weeks)

\begin{tabular}{|c|c|c|c|}
\hline Study & Factor & Coefficient & p Value \\
\hline \multirow[t]{2}{*}{ Term AGA (N) } & Maternal age (years) & 0.14 & 0.001 \\
\hline & Breast milk given $(1=y, 2=n)$ & -1.5 & 0.001 \\
\hline \multirow[t]{3}{*}{ Term AGA (I) } & Breast milk given $(1=y, 2=n)$ & -1.65 & 0.001 \\
\hline & Maternal smoking $(1=\mathrm{n}, 2=\mathrm{y})$ & -1.9 & 0.001 \\
\hline & Birth weight $(\mathrm{kg})$ & -1.0 & 0.014 \\
\hline \multirow[t]{2}{*}{ Preterm (B) } & Maternal smoking (1=n, 2=y) & -2.0 & 0.005 \\
\hline & Proportion of human milk (\%) during neonatal period & 0.04 & 0.006 \\
\hline
\end{tabular}

milk (or no human milk) during the neonatal period and maternal smoking during pregnancy. Birth weight, weight at 6 weeks, and weight gain between birth and 6 weeks after term were not predictors of weaning age, whether expressed as absolute measurements or as standard deviation scores.

\section{DISCUSSION}

We used data collected from a series of prospective randomised trials of infant nutrition to investigate weaning practices and the factors associated with these practices in infants born both term and preterm. As expected, and in accordance with nationally representative figures for the United Kingdom as a whole in the mid-1990s, the mean age at weaning was less than the minimum 4 months currently recommended. To some extent, this may reflect the fact that DoH advice changed from a recommended minimum of 3 months to 4 months in 1994, during the course of our studies, and the different advice may have taken a while to filter through. However, the proportion of infants already receiving solids at 6 weeks of age in our most recent term study was actually higher than in the two earlier studies, which would not support this explanation. A recent study performed in Tayside ${ }^{20}$ found that, although most mothers of term infants attending focus group discussions on infant feeding were aware of the DoH 4 month minimum guideline for weaning, almost one half had introduced (or were planning to introduce) solids before this age. Mothers believed that the introduction of solids was baby led and initiated by some physical characteristic or behavioural action of the infant.

Although our studies were not designed primarily to investigate weaning practices, information on the age of weaning was recorded for all infants prospectively in six studies, and retrospectively in one study. In addition, data were recorded on a variety of social and educational factors as well as infant anthropometry. This enabled us to examine the association between a variety of factors and the introduction of solids, and to look in a limited way at the association between birth weight, early weight gain, and weaning age. The fact that the results obtained from our term AGA cohorts are very similar to those from the larger, nationally representative Infant feeding survey conducted in 1995 suggests that our data are robust. Data from the 2000 Infant feeding survey have recently been published and show a movement towards later introduction of solids, with $24 \%$ of mothers weaning by 3 months of age compared with $56 \%$ in 1995 . However, $85 \%$ of mothers in 2000 had still introduced solids before 4 months.

\section{Term AGA and SGA cohorts}

Of interest, and to our knowledge not previously reported, was the finding that SGA term infants, whether formula or breast fed were significantly less likely than AGA infants to receive solids by 12 weeks of age. We speculate that this may reflect greater parental concern and a greater willingness on their part to adhere to guidelines because of the perceived vulnerability of their infant. There are no specific national or international guidelines for weaning in SGA infants even though this group represents $10 \%$ of births, and these infants undoubtedly have increased nutrient requirements compared with AGA infants. The 2000 Infant feeding survey includes a group of infants with birth weight below $2500 \mathrm{~g}$, although, as gestational age is not reported, it is not clear if they are term SGA or preterm. Nevertheless, these infants were less likely to have been given solids at both 6 and 12 weeks than babies with higher birth weights. ${ }^{13}$

As reported previously, formula feeding was a strong predictor of earlier solid feeding, but was not the only important factor. In simple regression analyses, maternal education and social class were significantly associated with weaning age. However, when other factors were considered in multiple regression models a different picture emerged. Early weaning was associated with formula feeding, younger maternal age, and maternal smoking. The fact that formula feeding and maternal smoking were stronger predictors of weaning age than maternal education or social class suggests that earlier weaning may primarily reflect less "positive health behaviours" in these mothers.

As reported in the Infant feeding survey, ${ }^{13}$ higher birth weight was also a strong predictor of earlier weaning. However, when weight at 6 weeks was included in the model, this proved a stronger predictor than either birth weight or change in weight between birth and 6 weeks. This suggests that the absolute size attained at 6 weeks of age is more influential than the growth trajectory of the infant before this point.

In both AGA and SGA groups, infants who were already receiving solids were heavier at 12 weeks of age than those who were not. Similar findings were reported by Forsyth et al. ${ }^{21}$ This could be because heavier infants are weaned earlier, or because the earlier introduction of solids is associated with more rapid subsequent weight gain. The fact that higher weight at 6 weeks (before weaning in most infants) was associated with earlier weaning supports the former explanation. However, it still does not resolve the issue of whether weaning is biologically driven (the heavier baby genuinely requiring and demanding solid food) or whether social factors are more important (the mother interpreting the larger size of her infant as indicating a need for solid food). To some extent, these factors may be interrelated.

\section{Preterm infants}

As there is no guideline for the optimal age for weaning in preterm infants, it is perhaps not surprising that, in these infants, over three quarters of the population were receiving solid food by 12 weeks corrected age. In a recent study involving 253 preterm infants born in Surrey, the mean post-term 
age at introduction of solids was 11.5 weeks, with earlier weaning in formula fed infants compared with breast fed or mixed fed infants. ${ }^{22}$ Interestingly, a recent multinational study of preterm infants with prospectively recorded data on weaning ${ }^{23}$ found that, whereas $98 \%$ of British preterm infants had received solids by 4 months after term, the figures were lower for American infants (67\%) and those in Chile (41\%). British infants were also more likely to have multiple types of food introduced at one time. There is no published information on what mothers are advised by their healthcare professionals in the United Kingdom, and it is likely that the DoH (1994) "5 kg guideline" is not widely promoted. There is clearly a need for evidence based guidelines. Results of a randomised controlled trial of 58 preterm infants found that the introduction of solid food at 12 weeks from birth compared with 14 weeks from term (the control group) results in enhanced length and haemoglobin status at 12 months. ${ }^{6}$ However, longer term consequences of this intervention have not yet been reported.

The finding that breast fed preterm infants were weaned later than formula fed infants is of potential concern in the light of their known slower growth during the period after discharge. ${ }^{4}$ Although the use of a nutrient enriched formula after discharge rather than standard term formula combined with breast feeding is a potential way of improving nutrient intake in these infants, some breast feeding mothers may wish to avoid using infant formula. Such infants may benefit from the earlier introduction of solid foods, especially foods rich in iron and zinc.

We found that earlier weaning in preterm infants was associated with the consumption of less human milk during the neonatal period and with maternal smoking during pregnancy. As is the case with term infants, this suggests that earlier weaning is associated primarily with less positive health behaviour. There was some evidence that use of a nutrient enriched formula after discharge was associated with earlier introduction of solids in preterm infants. Infants receiving this formula were heavier than those receiving term formula at 6 weeks, so there may have been an effect of weight on weaning practice as seen in term infants. Interestingly, term SGA infants randomised to the same formula after discharge in a parallel trial were no more likely to be weaned at 6 weeks than those fed term formula, but the differences in body weight between the two groups at 6 weeks of age was smaller in this study.

\section{Conclusions}

Our results reinforce national figures and anecdotal observations that mothers cannot or will not follow national guidelines on the age at which solids should be introduced. This may in part reflect the fact that current weaning recommendations are not adequately evidence based. Most infants in the United Kingdom today appear to thrive and show little short term morbidity, perhaps leading to a feeling that weaning practices are not an important public health issue. However, there is evidence that the introduction of solids before 4 months of age may be associated with increased body fat, higher body mass index, and a greater incidence of wheezing and respiratory illness in mid-childhood. Moreover, infant growth rate, which may be influenced by weaning practices, is increasingly recognised as having important consequences for later health. Thus it is important that weaning policy should be based on outcome studies in this area, which are currently lacking.

Our data suggest that, if the DoH does move towards the 6 month WHO recommendation, it is likely that this will be difficult to implement, as only $2 \%$ (eight of 388 ) of AGA infants achieved this in our study. Perhaps if weaning recommendations were seen to be more evidence based, particularly in relation to longer term health, both parents and health professionals might be more motivated to comply.

\section{ACKNOWLEDGEMENTS}

We thank Professor Brian Wharton for helpful comments on an earlier version of the manuscript.

\section{Authors' affiliations}

M S Fewtrell, A Lucas, MRC Childhood Nutrition Research Centre, Institute of Child Health, 30 Guilford Street, London WCIN 1EH, UK J B Morgan, School of Biomedical and Life Sciences, University of Surrey, Guildford, Surrey, UK

\section{REFERENCES}

1 Barker DJP, Winter PD, Osmond C, et al. Weight in infancy and death from ischaemic heart disease. Lancet 1989;ii:577-80.

2 Barker DJP, Hales CN, Fall CHD, et al. Type 2 (non-insulin-dependent) diabetes mellitus, hypertension and hyperlipidaemia (syndrome X): relation to fetal growth. Diabetologia 1993;36:62-7.

3 Fewtrell MS, Morley R, Abbott RA, et al. Catch-up growth in small for gestational age term infants: a randomized trial. Am J Clin Nutr $2001 ; 74: 516-23$

4 Lucas A, Fewtrell MS, Abbott RA, et al. Randomised trial of nutrient enriched formula versus standard formula for post-discharge preterm infants. Pediatrics 2001;108;703-11.

5 Wilson AC, Forsyth JS, Greene SA, et al. Relation of infant diet to childhood health: the Dundee infant feeding survey. BM 1998;316:21-5.

6 Foote K, Marriott LM, Kimber AC, et al. A randomised controlled trial of an evidence-based weaning strategy designed specifically to meet the needs of preterm infants. Arch Dis Child 2002;86: 1A.

7 Lanigan J, Bishop JA, Kimber AC, et al. Systematic review concerning the age of introduction of complementary food to the health full-term infant. Eur J Clin Nutr 2001;55:309-20.

8 DHSS (Department of Health and Social Security). Present day practice in infant feeding. Report on health and social subjects no 9 London: HMSO, 1974

9 DHSS (Department of Health and Social Security). Present day practice in infant feeding. Report on health and social subjects no 20. London: HMSO, 1980.

10 DHSS (Department of Health and Social Security). Present day practice in infant feeding: third report. Report on health and social subjects no 32. London: HMSO, 1988.

$11 \mathrm{DoH}$. Department of Health. Weaning and the weaning diet. Report on health and social subjects no 46. London: HMSO, 1994

12 Foster K, Lader D, Cheesbrough S. Infant feeding 1995. London: Office for National Statistics, The Stationary Office, 1997

13 Hamlyn B, Brooker S, Lleinikova K, et al. Infant feeding 2000. London: TSO, 2002.

14 WHO. Infant and young child nutrition. Global strategy on infant and young child feeding. WHO 55th World Health Assembly, 16 April 2002. A55/15. http://www.who.int/gb/EBWHA/PDF/WHA55/ ea5515.pdf.

15 Lucas A, Stafford M, Morley R, et al. Efficacy and safety of long-chain polyunsaturated fatty acid supplementation of infant-formula milk: a randomised trial. Lancet 1999;354:1948-54.

16 Morley R, Abbott R, Fairweather-Tait S, et al. Iron fortified follow on formula from 9 to 18 months improves iron status but not development or growth: a randomised trial. Arch Dis Child 1999:81:247-52.

17 Kennedy K, Fewtrell MS, Morley R, et al. Double-blind randomised trial of a synthetic triglyceride (Betapol) in formula fed term infants: effects on stool biochemistry, stool characteristics and bone mineralisation. Am J Clin Nutr 1999:70:920-7.

18 Lucas A, Fewtrell MS, Davies PSW, et al. Breastfeeding and catch-up growth in infants born small for gestational age. Acta Paediatr 1997;86:564-9

19 Morley R, Cole TJ, Powell R, et al. Mother's choice to provide breast milk and developmental outcome. Arch Dis Child 1988;63:1382-5.

20 Anderson AS, Guthrie C-A, Alder EM, et al. Rattling the plate: reasons and rationales for early weaning. Health Educ Res $2001 ; 16: 471-9$.

21 Forsyth JS, Ogston SA, Clark A, et al. Relation between early introduction of solid foods to infants and their weight and illnesses during the first two years of life. BM 1993:306:1572-6.

22 Norris FJ, Larkin MS, Williams CM, et al. Factors affecting the introduction of complementary foods in the preterm infant. Eur J Clin Nutr 2002;56:448-54

23 Yee J, Smith AM, O'Connor DL, et al. Introduction of complementary foods in preterm infants varies among countries. J Am Diet Assoc 2001;101:A76. 